\title{
Subjective Well-Being in Relation to Altruism and Forgiveness Among School Going Adolescents
}

\author{
Snigdha Pareek ${ }^{1, *}$, Madhu Jain ${ }^{2}$ \\ ${ }^{1}$ Institute of Health Management Research, F-226, Janpath, Shyam Nagar Extn., Jaipur, Rajasthan, 302019, India \\ ${ }^{2}$ Department of Psy chology University of Rajasthan A-70A, Urmila Path, Hanuman Nagar, Jaipur, Rajasthan, India
}

\begin{abstract}
In the study of subjective well being in relation to forg iveness and altruism a mong 100 schoolgoing adolescents (50 male and 50 female), the following tools and techniques were used to measure different variables: SUBJECTIVE WELL-BEING INVENTORY by Nagpal and Sell (1985) was used to measure Subjective Wellbeing, THE HELPING ATTITUDE SCA LE BY Nickell (1998) was used to measure Altru ism and THE HEARTLAND FORGIVENESS SCALE by Thompson et. al.(2005) was used to measure Forg iveness. On the basis of multiple regression it has been known that the predictive value of Forgiveness (Self, Others, Situation) is questionable or the measure of Forg iveness (Self, Others, Situation) does not enhance the prediction of subjective well-being whereas, Altruis $m$ does enhance the prediction of subjective well-being. The present study is carried out to exp lore the effect on subjective well-being of adolescents in the light of their measures of altru ism and forgiveness. Moreover, attempt is also made to see the effect in context of gender differences.
\end{abstract}

Keywords Subjective Wellbeing, A ltruis m, Forgiveness, Adolescence, Multiple Reg ression

\section{Introduction}

Subjective well be ing is composed of life satisfaction, the presence of positive affect, and the absence of negative affect. Thus, a person is described as enjoying a high level of SWB if he/she is satis fied with life, frequently experiences positive emotions and seldom feels negative emotions. It is an important aspect of one's psychological disposition and a mental state that helps a person to maintain equilibrium, anchored in hope and optimism, even during the adversities of life [1].

Forgiveness is a willingness to abandon one's right to resentment, negative judgment, and indifferent behavior toward one who unjustly hurt us, while fostering the undeserved qualities of compassion, generosity and even love toward him or her" [2].

Altruism is behavior that is aimed at benefiting another person. Altruistic behavior can be motivated by personal egotism, or it can be prompted by "pure" empathic desire to benefit another person, irrespective of personal gain[3].

Studies have examined associations between forgiveness and negative affective states, as well as positive outcomes such as life satisfaction, quality of life and well-being where in a number of studies inverse associations between forgiveness and negative affective states such as, depression, anxiety, anger or vengefulness have found[4,9-12]. There is

* Corresponding author:

snigdha_pareek@yahoo.co.in (Snigdha Pareek)

Published online at http://journal.sapub.org/ijpbs

Copyright (C) 2012 Scientific \& Academic Publishing. All Rights Reserved a positive association between measures of unforgiveness and depression, anxiety, anger, negative affects and beliefs and even PTSD[13-16].

The important role of empathy in forg iveness is qualified by gender. Women have higher levels of empathy than do men. Findings also indicate that empathy may have a greater impact for men in facilitating the process of forgiveness [17].

Gender and age in particular are robust determinants of SWB across samples. Generally, wo men report higher SWB scores than men do, and SWB is U-shaped with age: SWB is higher among young people, declines in middle age cohorts and increases again at older age. Thus the present study is conducted to examine the relationship among altru ism, forgiveness and subjective well being among adolescents.

\section{Method}

\section{Participants}

A sample of 100 schoolgoing adolescents ( 50 boys and 50 girls) aged between 14- 17 years was selected using purposive sampling technique on the availability as well as on the willingness to participate in the study. Respondents were selected fro $m$ the reputed public co-educational school of Jaipur city (District of Rajasthan), namely Children's Academy.

\section{Measures}

The following tools were used in the present study:

1. SUBJECTIVE WELL BEING INVENTORY: SWB developed by Nagpal and Sell[18], is a self report questionnaire consisting of 40 items designed to measure an 
individual's mental status regarding overall feeling about life. The inventory gauges eleven factorial dimensions namelyPositive affect, Expectation achievement congruence, confidence in coping, Transcendence, Family group support, Social support, Primary group concern, Inadequate mental mastery, Perceived ill-health, Deficiency in social contacts and General wellbeing negative affect. For positive items, score is 3,2 and 1 respectively and vice-versa for the negative items. The sum of all 40 items gives overall Subjective Wellbeing score. Higher the score, shows better the Subjective Well Being and vice-versa. The scale has been found to have high inter-rater, inter-scores, and test-retest reliability and has proved its validity through many experiments[19, 20] and was therefore considered appropriate for this study.

2. THE HELPINGATTITUDE SCALE (HAS): It is a self administered questionnaire developed by G.S. Nickell[21] that consists of 20 items measure that tap beliefs, feelings and behaviours related to helping. It meets the psychometric criteria for scale reliability and validity. The internal consistency for the sacle (Cronbach's Alpha) was .869. Overall, a statistically significant, test-retest correlation was found, $\underline{\mathrm{r}}(56)=.837, \underline{\mathrm{p}}<.001$. Based on Batson's (1991)[22] empathy-altru ism hypothesis, the HAS was predicted to be strongly related to the Empathic Concern (EC) subscale with $\underline{\mathrm{r}}(114)=.526, \underline{\mathrm{p}}<.001$. Each item on the questionnaire has to be rated on a 5-point scale. Higher ratings indicated high altruis $\mathrm{m}$.

3. THE HEA RTLAND FORGIVENESS SCALE (HFS): It is a self administered questionnaire developed by Thompson[23] consisting of 18 items trait measure of forgiveness. There are six items to tap each of the three types of forg iveness- self, others or situation. Each item on the questionnaire has to be rated on a 7-point scale. Scores on the HFS have correlated positively with scores on other forgiveness measures; people scoring higher on HFS also show more flexibility and trust, as well as less hostility, rumination and depression.

\section{Results and Discussions:}

Table 1. Predict ors of Subjective Well-being for Male Sample using step wise Multiple Regression Analysis

\begin{tabular}{|c|c|c|c|c|c|c|}
\hline Predictors & $\mathrm{R}$ & $\mathrm{R} 2$ & $\begin{array}{c}\text { Adjusted } \\
\mathrm{R} 2\end{array}$ & $\mathrm{~B}$ & $\mathrm{~F}$ & $\mathrm{P}<$ \\
\hline Altruism & $.150(\mathrm{a})$ & .022 & .002 & .101 & 1.098 & N.S. \\
\hline $\begin{array}{c}\text { Forgiveness } \\
\text { of Self }\end{array}$ & $.364(\mathrm{a})$ & .132 & .114 & .570 & 7.331 & 0.01 \\
\hline $\begin{array}{c}\text { Forgiveness } \\
\text { of others }\end{array}$ & $.001(\mathrm{a})$ & .000 & -.021 & -.001 & .000 & N.S. \\
\hline $\begin{array}{c}\text { Forgiveness } \\
\text { of Situation }\end{array}$ & $.423(\mathrm{a})$ & .179 & .162 & .672 & 10.468 & 0.01 \\
\hline
\end{tabular}

In order to examine the extent to which weighted combination of various variables included in the study predicts the criterion variable, step wise multiple regression was applied. Stepwise multiple regression was employed to identify the factors that account for maximum proportion of the variance in subjective wellbeing, the criterion variable and to eliminate those that do not make additional contribution to the variables already in question. In the present study, there were four predictor variables i.e. altruis $m$ and three subscales of forgiveness.

Multiple Regression Output for the male sample of adolescents is presented in Table-1:

On analyzing differently with males (Table 1), it was found that the multiple regression for male sample suggests that Forgiveness of Self and Situation meet the criteria. Forgiveness of self and Forgiveness of Situation predictive values are positively significant at 0.01 level. This means that Forgiveness of self and Forgiveness of Situation as predictors do affect the subjective well-being as a dependent or criterion variable. But A ltruis m and forgiveness of others do not enhance subjective wellbeing in male sample. The most significant predictor came out to be Forgiveness of Situation with $\mathrm{R}$ equal to 0.423 and $\mathrm{R}^{2}$ equal to 0.179 $(\mathrm{F}=10.468, \mathrm{P}<.01)$. This shows that Forgiveness of Situation along with all other variables account for $17.9 \%$ of variance in subjective well-being and by itself accounted for $16.2 \%$ variance $(\mathrm{R} 2$ change $=0.162)$ when considered alone. The next significant predictor came out to be Forgiveness of Self with $\mathrm{R}$ equal to 0.364 and $\mathrm{R} 2$ equal to $0.132(\mathrm{~F}=7.331$, $\mathrm{P}<.01)$. This shows that Forgiveness of Self along with Altruism account for $13.2 \%$ of variance in subjective well-being and by itself accounted for $11.4 \%$ variance (R2 change $=0.114$ ) when considered alone. According to this finding it can be said that male adolescents high on subjective well-being, with a high life satisfaction have Forgiveness of Situation and Self traits higher to enhance their subjective well-being. The male adolescents who easily forgive the situations which cause difficulty and themselves for any mishap are high on subjective well-being.

The regression coefficient ' $\mathrm{B}$ ' of Forgiveness of self and Forgiveness of Situation is 0.570 and 0.672 respectively; the direction of influence for Forgiveness of self and Forgiveness of Situation predictors is positive. The $t$ value of Forgiveness of self and Forgiveness of Situation is significant ( $\mathrm{t} F$. Self $=2.708$ and $\mathrm{t} F$. Sit. $=3.235$ ). This means that Forgiveness of self and Forgiveness of Situation predict subjective well-being above and beyond what other variables do.

Table 2. Predictors of SWB of Female Sample using step wise multiple regression analysis

\begin{tabular}{|c|c|c|c|c|c|c|}
\hline Predictors & $\mathrm{R}$ & $\mathrm{R} 2$ & $\begin{array}{c}\text { Adjusted } \\
\mathrm{R} 2\end{array}$ & $\mathrm{~B}$ & $\mathrm{~F}$ & $\mathbf{P}<$ \\
\hline Altruism & $.547(\mathrm{a})$ & .299 & .285 & .454 & $\mathbf{2 0 . 4 8 7}$ & 0.01 \\
\hline Self & $.178(\mathrm{a})$ & .032 & .012 & .237 & 1.571 & N.S. \\
\hline Others & $.183(\mathrm{a})$ & .033 & .013 & .340 & 1.655 & N.S. \\
\hline Situation & $.043(\mathrm{a})$ & .002 & -0.019 & -.066 & .089 & N.S. \\
\hline
\end{tabular}

On analyzing differently with females (Table 2), it was found that the multiple regression for female sample suggests that Altruism meets the criterion. Only altruism predictive value is positively significant at 0.01 level in female sample. This means that altruis $m$ as a predictor does 
affect the subjective well-being as a dependent or criterion variable. But forg iveness (self, others and situation) does not enhance subjective wellbeing in the female sample. The most significant predictor came out to be altruism with $\mathrm{R}$ equal to 0.547 and $\mathrm{R}^{2}$ equal to $0.299(\mathrm{~F}=20.487, \mathrm{P}<.01)$. This shows that altruis $m$ accounts for $29.9 \%$ of variance in subjective well-being and by itself accounted for $28.5 \%$ variance ( $\mathrm{R} 2$ change $=0.285$ ) when considered alone. According to this finding it can be said that female adolescents high on subjective well-being, with a high life satis faction have altruistic behaviour to enhance it very much. The altruis $m$ enhances their subjective well-being in a very effective way.

The regression coefficient ' $\mathrm{B}$ ' of Altruism for female sample is 0.454; the direction of influence for Altruis $\mathrm{m}$ is positive. The $t$ value of altruism is significant $(t$ altr. $=4.546)$. This means that Altruism predicts subjective well-being above and beyond what other variables do in the female sample. This finding supports the fact that altruistic behavior in adolescent girls enhances their subjective well-being in more effective way than others.

In female sample of adolescents, multiple regression confirms that the predictive values of Forgiveness (Self, Others, Situation) are questionable or the measures of Forgiveness (Self, Others, Situation) do not enhance the prediction of subjective well-being whereas, Altruism does enhance the prediction of subjective well-being.

Table 3. Predict ors of Subjective Well-being for Total Sample using step wise Multiple Regression analysis

\begin{tabular}{|c|c|c|c|c|c|c|}
\hline Predictors & $\mathrm{R}$ & $\mathrm{R}^{2}$ & $\begin{array}{c}\text { Adjusted } \\
\mathrm{R}^{2}\end{array}$ & $\mathrm{~B}$ & $\mathrm{~F}$ & $\mathrm{P}<$. \\
\hline Altruism & $.318(\mathrm{a})$ & .101 & .092 & .233 & 11.035 & .01 \\
\hline $\begin{array}{c}\text { Forgiveness } \\
\text { of Self }\end{array}$ & $.265(\mathrm{a})$ & .070 & .061 & .381 & 0.00 & N.S. \\
\hline $\begin{array}{c}\text { Forgiveness } \\
\text { of others }\end{array}$ & $.069(\mathrm{a})$ & .005 & -.005 & .100 & .464 & N.S. \\
\hline $\begin{array}{c}\text { Forgiveness } \\
\text { of Situation }\end{array}$ & $.181(\mathrm{a})$ & .033 & .023 & .268 & 3.326 & N.S. \\
\hline
\end{tabular}

Multiple regression analysis (Table 3) for total sample of adolescents suggests that only altruis m meet the criterion. Only altruism predictive value is positively significant at 0.01 level. This finding goes with the findings with female sample of adolescents. This means that altruis $m$ as a predictor does affect the subjective well-being as a dependent or criterion variable. But forgiveness (self, others and situation) does not enhance subjective wellbeing ( $\mathrm{F}=$ $0.00 \mathrm{P}<.01, \mathrm{~B}=.381$ for forg iveness of self; $\mathrm{F}=.464 \mathrm{P}<.01$, $\mathrm{B}=.100$ for forgiveness of others; $\mathrm{F}=3.326 \mathrm{P}<.01, \mathrm{~B}=.268$ for forg iveness of situation). The most significant predictor came out to be altruism with $\mathrm{R}$ equal to 0.318 and $\mathrm{R}^{2}$ equal to $0.101(\mathrm{~F}=11.035, \mathrm{P}<.01)$. This shows that altruism accounts for $10.1 \%$ of variance in subjective well-being and by itself accounted for $9.2 \%$ variance $(R 2$ change $=0.092)$ when considered alone. According to this finding it can be said that adolescents high on subjective well-being, with a high life satisfaction have altruistic behavior to enhance it which is reflected main ly due to the re lationship between altru is $m$ and
SWB in females.

The regression coefficient ' $B$ ' of Altruis $m$ is 0.233 ; the direction of influence for Altru ism is positive. The $t$ value of altruis $\mathrm{m}$ is significant $(\mathrm{t}$ altr. $=3.322)$. This means that Altruism predicts subjective well-being above and beyond what other variables do. This finding supports the fact that altruistic behavior enhances individual's subjective well-being in more effective way than others.

In total sample of adolescents, multip le regression confirms that the predictive values of Forgiveness (Self, Others, Situation) are questionable or the measures of Forgiveness (Self, Others, Situation) do not enhance the prediction of subjective well-being whereas, Altruis m does enhance the prediction of subjective well-being. Thus the result which came out in this combined analysis can be attributed to reflect the strength of the relationship in females between altruis $m$ and subjective well-being. It can also be supported by a similar study in which females obtained higher altruistic scores than males. It finds that females in general were more altruistic than males but this difference occurred only under certain pre-training and partner-sex conditions. Males were generally less responsive than females showing consistently riva lrous behaviour across all conditions [24].

A similar study finds that men are more likely to be either perfectly selfish or perfectly selfless, whereas women care more about equalizing payoffs [25]. In their study Eckel and Grossman[26] found all-female groups more altruistic than all-male groups.

One study suggests sex differences in the expression of altruis $m$ could be due to the female's reluctance to engage in aggression and high-risk situations -- often a prerequisite for altruistic behavior. This reluctance was associated on the part of women with differing socialization effects on the development of masculine and femin ine personalities. The reduced sense of efficacy in a demanding situation could certainly contribute to differing responses from men and women in behavior attributable to altru ism[27]. However, studies suggest that altruistic tendencies vary with respect to those with whom we are interacting. We have some capacity for unrequited altruis $m$ towards strangers; more capacity for altruis $m$ towards those who have engaged in reciprocal relations with us, and much greater altruism towards close kin[28].

Thus it appears that the relationship between altruism and subjective well-being is remarkable which is noteworthy in females as compared to males. Altruis m plays a role in enriching subjective well-being, mainly of female adolescents. However, males do not necessarily consider altruistic behavior as a mode to comprehend happiness, while females very much do. It can be attributed to the fact that females may reflect increasing awareness of social roles which they adopt and to fit the expectations of those roles they change their behavior and thus score high on altruism. Forgiveness of self and forgiveness of situation play a good role in elevating subjective well-being of adolescents. However males do exhibit the same relationship but the females do not. Above all a positive result was found 
between subjective well-being and predictor altruism which simply means that if it is present in an individual, he or she would defin itely have a high subjective well-being. Further investigation of the bidirectional influences of altruism, forgiveness and wellbeing could help in understanding the probable routes of influence among these three variables.

\section{REFERENCES}

[1] Diener, Suh, Lucas and Smith, Subjective Well-being: Three decades of progress. Psychological Bulletin, vol. no. 125, 276-302, 1999.

[2] Enright, R. D., Freedman, S., \& Rique, J., The psychology of interpersonal forgiveness, Exploring forgiven ess, Madison, WI: University of Wisconsin. pp. 46-62, 1998.

[3] Batson, C.D. \& Oleson, K.C. Current status of the empathyaltruism hypothesis. In M.S. Clark (Ed.), Prosocial Behavior, Newbury Park, CA: Sage, pp. 62-85, 1991.

[4] Toussaint, L. L., Forgiveness and health: Age differences in a U. S. probability sample, Journal of Adult Development, vol. no. 8, 249-257, 2001.

[5] Krause, N., \& Ellison, C. G. Forgiveness by God, forgiveness of others, and psychological wellbeing in late life, Journal for the Scientific Study of Religion, vol. no. 42, 77-93, 2003.

[6] Berry, J. W., \& Worthington, E. L., Jr. Forgiveness, relationship quality, stress while imagining relationship events, and physical and mental health, Journal of Counseling Psychology, vol. no. 48, 447-455, 2001.

[7] Brown, R. P. "Measuring individual differences in the tendency to forgive: Construct validity and links with depression", Personality and Social Psychology Bulletin, vol. no. 29, 1-13, 2003.

[8] Brown, R.P. \& Phillips, A. "Letting bygones be bygones: Further evidence for the validity of the Tendency to Forgive scale." Personality and Individual Differences, vol. no. 38, 627-638, 2005.

[9] Exline, Yali, \& Lobel. "When God disappoints: Difficulty forgiving God and its role in negative emotion", Journal of Health Psychology, vol. no. 4, 365-379, 1999.

[10] Friedman, P., Forgiveness is a/the key to happiness, well-being and quality of life, International Quality of Life Conference. Philadelphia, Pa. 2004.

[11] Friedman, P., The Relative Contribution of Forgiveness, Gratitude, Prayer, and Spiritual Transcendence in Reducing Distress and Enhancing Well-Being, Quality of Life and Happiness, 3rd Annual Mid-Year Research Conference on Religion and Spiritua lity. Columbia, MD, 2005.

[12] Kendler, K. S., Dimensions of religiosity and their relationship to lifetime psychiatric and substance use disorders. American Journal of Psychiatry, vol. no. 160, 496-503. 2003.

[13] Mauger, P. A., The measurement of forgiveness: Preliminary research, Journal of Psychology and Christianity, vol. no.11, 170-180, 1992.

[14] Seybold, K. S., Physiological and psychological correlates of forgiveness, Journal of Psychology and Christianity, vol. no. 20, 250-259, 2001.

[15] Subkoviak, M. J., Measuring interpersonal forgiven ess in late adolescence and middle adulthood, Journal of Adolescence, vol. no.18, 641-655, 1995.

[16] Witvliet, C. V. O., Posttraumatic mental and physical health correlates of forgiveness and religious coping in military veterans. Journal of Traumatic Stress, vol. no.17, 269-273, 2004.

[17] Toussaint, L., \& Webb, J. R., Forgiveness, Mental Health and Well-Being, Handbook of Forgiveness. Routledge, New York, 2005.

[18] Sell, P. \& Nagpal, L.R., Assessment of subjective well being: The subjective well being Inventory (SUBI), Regional health paper, SEARO, New Delhi: WHO Regional office for South East Asia. 1992

[19] Grandall, R.: Validation of self -report measures using rating by others, Sociological Methods and Research, 4, No. 3, pp 380-400, 1976.

[20] Huisman, S.: Het meten van positieve aspecten van welzjin bij kankerpatienten, Doctoral Dissertation, Psychological Laboratory, University of Amsterdam.1981

[21] Nickel, G.S., The Helping Attitude Scale, American Psychological Association Convention, San Francisco, 1998.

[22] Batson, C. D. The altruism question: Toward a social psy chological answer. Hillsdale, NJ: Lawrence Er lbaum.1991

[23] Thompson, L.Y., Dispositional forgiveness of self, others, and situations: The Heartland Forgiveness Scale, Journal of Personality, vol. no. 73, 313-359, 2005.

[24] Skarlin Kurt \& Moely Barbara E. Altruistic Behavior: An analysis of age \& sex difference. Child Development, 47, 1159-1165, 1976.

[25] Andreoni, James \& Vesterlund, Lise. Which is the fair sex? Gender differences in altruism. The Quarterly Journal of Economics, Harvard College \& Massachusetts Institute of Technology, 294-307, 2001.

[26] Eckel, Catherine C., \& Philip Grossman, "Are Women Less Selfish than Men? Evidence from Dictator Experiments," Economic Journal, C VII, 726-735, $1997 \mathrm{~b}$.

[27] Ullian. D. Whv girls are good: a constructionist view. American Journal of Orthopsy chiatry, 54, 71-82, 1984.

[28] "Egoism, Altruism, and Our Cooperative Social Order." In Morality: The Why and What of It, edited by James Sterba. Boulder, CO: Westview Press, forthcoming www.gaus.biz/E goismAltruism.pdf 